\title{
On Commercial Advertisement Translation Based on Skopos Theory
}

\author{
Xiangxin Liu \\ ${ }^{1}$ Full address of first author, including countryDepartment of Public Relations, Wuhan Railway \\ Vocational Technological University, Wuhan, 430325, China
}

Keywords: Translation studies; Translation theory; Skopos theory; Advertising translation

\begin{abstract}
The paper illustrates firstly the importance of commercial advertisement translation, and then respectively introduces how to apply the Skopos theory to commercial advertisement translation and two different strategies. In the end, the paper gives a profound reflection on the present situation of commercial advertisement translation with confirming the value of Skopos theory.
\end{abstract}

\section{Introduction}

As the economic globalization is increasingly significant, circulation of international commodities is more and more frequent. In order to expand international market, introduce better products and services to target consumers and promote brand image, transnational companies treat advertising as an important strategy. There is no doubt that the success or failure of advertising translation affects the sale of goods to a great extent.

Commercial advertising translation is an activity with a long history, whose contribution for economic globalization is quite obvious and non-negligible. Studies on commercial advertising translation are significant to transnational business activities. What makes commercial advertising translation so available and reliable lies in its practicality, which may guide commercial advertising translation practice and improve the quality of commercial advertising translation and then help promote sales and improve the reputation of product, company and brand. However, commercial advertising translation has a particularity according to its style and function. The traditional translation criteria "faithfulness" and "equivalence" are hard to adapt to the flexibility of commercial advertising translation and explain some necessities to increase the adjustment of the phenomena such as addition, deletion and alteration. Some researchers tried to translate well from aspects of language, culture, psychology, trans-culture and so on ,but they have no specific and reliable theory that can support their points. Since a long time ago, commercial advertising translation went on below expectation. But after Skopos theory was created, commercial advertising translation became easy and satisfactory. Compared with other theories such as Adaptation theory, Acception theory and Functional Equivalence theory and so on, Skopos theory can explain very well. Skopos theory regards translation as a purposeful communicative behavior. It puts the intended purpose of translation on the top position, which provides theoretical basis for translators to flexibly apply translation methods and choose translation strategies in translating commercial advertising.

\section{The Necessity of Commercial Advertisement Translation}

Commercial advertisement translation is a cross-cultural communicative and commercial activity, and one of the most important ways to speed up globalization progress. The transnational companies need translator help them increase their profits by making product gain more and more popularity. With the development of economy and China's entry into WTO, China's commodity circulation with the rest of the world becomes more frequent. More and more foreign goods enter the Chinese market, and more and more Chinese enterprise products to the international market. To participate in international competition, enterprise will depend on advertising frequently. Today's era can be said to be an advertisement in a certain sense. Merchandise propaganda is an important means of international competition and promotion, and it is also a link for expanding international market. At the same time, it also opens a window for us to make investigation of the historical and cultural background, and it makes 
us understand the different social psychology. So, it puts forward higher requirements to us in commercial advertising translation. In order to succeed to realize the function of advertising, and to achieve the goal of advertising -- to attract the public attention and induce people to purchase, it usually emphasizes the ideal quality of product .

In fact, it is not easy to deal with commercial advertising translation. In the process of commercial advertising translation translators should pay attention to the readers' cultural identity, and to cater the reader's customs, experience, belief, value, rank, religion and so on. In addition, product feature is very important for translator to consider. Otherwise, the advertisement translation will not be accepted, so that the product is difficult to be sales and occupy the market.

However, it is a pity that for a long time commercial advertising translation has not got a systemic theory to support its development. Certainly, on the one hand, the translators' negligence to it does not mean that to study commercial advertising translation theoretically is unnecessary. On the other hand, to study commercial advertising translation it is really hard for translators from only one aspect. However, it is like a mission this era entrusts to translators.

\section{The Three Principles of Skopos Theory}

Skopos theory is an important translation theory of functional school. Its theory of behavior and cross-cultural communication theory is the theoretical basis, which points out that any act has its purpose. Translation is a behavior to achieve the cross-cultural information and cross-language conversion (Lai Youxiang 200-201), thus translation behavior is also a purposeful behavior. Vermeer's Skopos theory thought that "all translation should follow three principles: a. skopos principle; b. coherence principle; c. loyal principle; among which skopos principle is the first principle. Some scholars pointed out that the whole translation process depends on the purpose of translation behavior. Coherence principle refers to the consistency of the target language, that is, the target language readers are able to understand the meaning of advertising, and advertising text is in line with their language expression habits and cultural habits. Loyal principle refers to that the source language is consistent with the target language, that is, according to the source language it can find similar or similar expression in the target language. Commercial advertisement translation is a purposeful translation, so translators can translate it based on the Skopos theory.

Skopos Principle. To achieve translation purpose, it allows that translators to make some appropriate adjustment to deal with the "non-faithfulness" translation or the "non-equivalence" translation in the process of translation, (Li Kexing 2010) such as deleting invalid information. Brevity is the basic requirement of commercial advertising information. The long and drag advertising words are not convenient for consumers to accept and memory, because it is easy to hinder the achievement of translation. Due to cultural differences, the original and translational recipients' aesthetic taste and value orientation are different. So, the information appeals to the source language consumers is not necessarily effective to the target language consumers. Therefore it requires that, in the process of translation the translators should be able to distinguish valid and invalid information and boldly delete inactive information. For example, in the aspect of food advertising, Chinese people believe in authority, so the Chinese advertising often advertises "authoritative attestation", "provincial and ministerial quality " and so on, but in western countries, people may pay more attention to individual taste, not particularly care about official comments, so the information that has lost its meaning in the target language should be omitted while translating.

Coherent Principle. To achieve the translation purpose, it is necessary to ensure the coherence of the target language. In the aspect of language habits, Chinese is in twists and turns, but English is straightforward. In the Chinese advertising, it often foreshadows something first, and then leads to theme. In English advertising, on the contrary, it comes to the point and be concise and comprehensive. Chinese tends to use four words idioms and dual words according to Li Kexing (2010), but English commonly uses the cohesion word such as conjunctions, prepositions and segmentation. Only translators familiar with the different language habits of both Chinese and English can them stand on the point of the source language readers and follow their habits to attract the attention of consumers, and 
then stimulate consumers' buying desire. In terms of culture, in order to avoid advertising communication obstacles leaded by the cultural background differences, cultural transformation should be appropriately applied to translation. Especially in the advertising translation with strong national culture color, translators often need to use paraphrase to facilitate consumers to understand and accept. So, in the application of the approach of Skopos theory, thanslators should be bold to break through the bondage of the source text, and not constrained by the form and content of the source text. And translators should be good at using the method of conversion and creation to flexibly reappear the function of the source text, which can make the target language readers be able to understand and willing to accept.

Loyal Principle. To achieve the translation purpose, the target language text should be consistent with the source language text. Commercial advertising text is a kind of application text, if the translation method that was applied to the research text was used to translate advertisement, the purpose of commercial advertising translation would be not worth the candle. Research text such as philosophy text, religion text and classic text, emphasizes the faithfulness to the original purpose and even the sentence form, so the frequency of the literal translation is quite high. However, literal translation is not satisfying in commercial advertising translation.

\section{The Strategies of Commercial Advertisement Translation Under Skopos Theory}

The ultimate goal of commercial advertising translation is the realization of the function of advertising, which can effectively introduce products to consumers, and recognized by the consumers to buy the products. If translators only treat "faithfulness" and "equivalence" as the standard of translation, and in the process of advertising translation always stick to the original text, even if the translation is faithful and equivalent to the original text, it may not achieve the desired effect of advertisement, and also as $\mathrm{Li}$ Kexing says "in advertising translation, being faithful to the original text is not necessarily vested, and also style is not necessarily consistent with the original text, the excess translation (over translation) and the distorted translation (under translation) are acceptable, as long as the foreseeable effect of advertising translation is good."

In commercial advertisement, product is the main propaganda object. And the object of product is consumer. So, it requests translators take notice of product and consumers in the process of commercial advertising translation. Therefore, in the aspect of translation strategies, translators can choose consumer-centered strategy as well as product-centered strategy. No matter which kind of strategy is chosen by translators, the ultimate goal of commercial advertising translation is to make consumers desire to buy the product.

Consumer-centered Strategy. Consumer-centered strategy is that the translators stand in the consumers' position to make the consumers be able to understand and accept the products described in the translation, meanwhile giving the products an effect that maximizes the satisfaction of the consumers' needs. At last, it will lead consumers to produce a desire to purchase products.

Product-centered Strategy. Product-centered strategy is that translators stand on the commercial company's point of view to strongly praise the quality attributes of the products so that the products meet the tastes and needs of consumers after the translation, and then promote products to consumers and promote enterprise sales so that the economic benefits of enterprise are improved. At last, it will lead products produce a charm that attracts consumers to buy them.

\section{Summary}

The translation text does not have to "faithfully" imitate the original text. If commercial advertisement translation is constrained by "equivalence" and "faithfulness", certainly it will be unable to achieve the purpose and function of the translation text. To obtain the ideal translation, advertising translators need to flexibly choose translation strategy for the intended purpose. Sometimes advertising translators need to omit invalid information and adjust the translation text according to the language, culture, laws and regulations of target language. Commercial advertising is a kind of competitive business behavior, and 
its purpose is to strive to gain consumers, making consumers accept and buy the products, and this is the ultimate goal as well as the purpose of commercial advertising translation. The particularity of commercial advertising translation determines that the Skopos theory has directive significance and applicability for commercial advertising translation.

\section{References}

[1] Bassnet, Susan \& Lefevere, Andre. Constructing Cultures[M]: Essays on Literary Translation, Cleveton: Multilingual Matters, 1998.

[2] Catford, J. C. A Linguistic Theory of Translation [M]. London: Oxford University Press, 1965.

[3] Jakobson, Roman. Theories of Translation [M]. The University of Chicago Press, 1992.

[4] Nida, E. Language, Culture, and Translating[M]. Shanghai Foreign Language Education Press, 1993.

[5] VERSCHUEREN, JEF. Understanding Pragmatics [M]. Beijing: Foreign Language Teaching and Research Press, 2000. 